\title{
Aoristo)))))
}

International Journal of Phenomenology, Hermeneutics and Metaphysics

\section{"Aber ich fühle noch eine andere Berufung in mir" Drei große Karmelitinnen zum Frauen-Priestertum}

\author{
"But | feel another calling in me" \\ Three great Carmelites for the women's priesthood
}

Pe. Dr. Ullich Dobhan OCD

Provinzialat der Teresianischen Karmeliten, München'

Zu den am meisten diskutierten Themen in unserer Kirche gehören zurzeit die Frage nach dem Pflichtzölibat und der Priesterweihe für Frauen. Während es seit der apostolischen Zeit und bis ins weit Mittelalter hinein viele Belege für verheiratete Priester gibt, und auch heute in der römisch katholischen Kirche solche oft sehr segensreich wirken, gibt es für das Frauenpriestertum diese Tradition nicht, abgesehen von biblisch bezeugten Diakoninnen. So spricht Paulus im Römerbrief $(16,1)$ von der diakonä (griech.) - Diakonin Phöbe. (In der Einheitsübersetzung von 2016 steht an dieser Stelle immer noch geglättet „Dienerin“, statt Diakonin.) Die Gründe, die immer wieder gegen das Diakonat der Frau und das Frauenpriesterum ins Feld geführt werden, brauche ich nicht zu wiederholen, doch möchte ich darauf hinweisen, wie die drei großen Frauen des Teresianischen Karmel darüber denken.

Teresa von Ávila (1515-1582), 1970 als erste Frau zur Kirchenlehrerin ernannt, hat zeitlebens unter der Unterdrückung durch Männer in Kirche und Gesellschaft gelitten und wagt, das auch zu formulieren, was allerdings dann der Zensur durch Männer zum Opfer fiel: „Du, Herr meiner Seele, dir hat vor den Frauen nicht gegraut, als du durch diese Welt zogst, im Gegenteil, du hast sie immer mit großem Mitgefühl bevorzugt, und hast bei ihnen genauso viel Liebe und mehr Glauben gefunden als bei den Männern, denn es war da deine heiligste Mutter, durch deren Verdienste - und weil wir ihr Gewand tragen - wir das verdienen, was wir wegen unserer Schuld nicht verdient haben. Reicht es denn nicht, Herr, dass die Welt uns eingepfercht und für unfähig hält, in der Öffentlichkeit auch nur irgendetwas für dich $\mathrm{zu}$ tun, was etwas wert wäre, oder es nur zu wagen, ein paar Wahrheiten

$\overline{{ }^{1} \text { E-mail: provinzialat@karmelocd.de }}$ 


\section{Aoristo)))))}

International Journal of Phenomenology, Hermeneutics and Metaphysics

auszusprechen, über die wir im Verborgenen weinen, als dass du eine so gerechte Bitte von uns nicht erhörtest? Das glaube ich nicht, Herr, bei deiner Güte und Gerechtigkeit, denn du bist ein gerechter Richter, und nicht wie die Richter dieser Welt, für die, da sie Söhne Adams und schließlich lauter Männer sind, es keine Tugend einer Frau gibt, die sie nicht für verdächtig halten" (Weg der Vollkommenheit [CE] 4,1 Neuausgabe 2015, Verweis auf Fußnote 6 mit der Erläuterung zum erst um das Jahr 2000 vollständig rekonstruierten Text dieses Zitates [vgl. CV 3,7], bis auf den ersten Satz des obigen Zitates).

Teresa beneidet den Franziskanermissionar "Alonso Maldonado mit denselben Wünschen nach dem Heil der Seelen wie ich, nur dass er sie ins Werk setzen konnte, so dass ich ganz neidisch auf ihn war" (Gründungen 1,7). 1577 schrieb sie in ihrem Hauptwerk Die Innere Burg; "Auf der anderen Seite würde sie sich am liebsten mitten in die Welt stürzen, um zu sehen, ob sie mithelfen könnte, damit auch nur eine Seele Gott mehr lobte. Und wenn es eine Frau ist, reibt sie sich wund an der Fessel, die ihr ihre Natur auferlegt, da sie das nicht tun kann, und ist neidisch auf diejenigen, die die Freiheit haben, um mit lauter Stimme zu verkünden, wer dieser große Gott der Reiterscharen ist" (6. Wohnung 6,3). Schon aus diesen wenigen, unter zahlreichen anderen Texten wird klar, dass es Teresas Wunsch war, eigentliche priesterliche Aufgaben auszuüben.

Dreihundert Jahre später schreibt eine ihrer größten Töchter im Karmel, wie sie auch Kirchenlehrerin, Therese von Lisieux (1873-1897): „Aber ich fühle noch andere Berufungen in mir, ich fühle die Berufung zum Krieger, zum Priester, zum Apostel, zum Kirchenlehrer, zum Märtyrer; kurz, ich spüre das Bedürfnis, den Wunsch, für dich, Jesus, die heroischsten Werke allesamt zu vollbringen... Ich spüre in meiner Seele den Mut eines Kreuzfahrers, eines päpstlichen Soldaten, zur Verteidigung der Kirche möchte ich auf dem Schlachtfeld sterben... Ich fühle in mir die Berufung zum Priester; mit welcher Liebe trüge ich dich, o Jesus, in meinen Händen, wenn auf mein Wort hin du vom Himmel herabstiegest... mit welcher Liebe reichte ich dich den Seelen! Jedoch, so sehr ich wünschte, Priester zu sein, so bewundere und beneide ich dennoch die Demut des hl. Franz von Assisi und spüre in mir die Berufung, ihn nachzuahmen, indem ich die erhabene Würde des Priestertums ausschlage." (Selbstbiographische Schriften 198). Was hätte man im Falle eines Mannes nicht alles unternommen, um diesen Herzenswunsch zu erfüllen!

Und in den 20er Jahren des 20. Jahrhunderts äußert sich eine weitere Karmelitin mit dem Namen Teresa Benedicta a Cruce (1891-1942), noch als Edith Stein - heute Kopatronin Europas - in einem ganz anderen literarischen Kontext, nämlich in einem Vortrag für die Katholische Akademikervereinigung in Aachen am 30. Oktober 1931 zum Thema Frauenpriestertum: „Die neueste Zeit zeigt einen Wandel durch das starke Verlangen nach weiblichen Kräften für kirchlich-caritative Arbeit und Seelsorgshilfe. Von weiblicher Seite regen sich Bestrebungen, dieser Betätigung wieder den Charakter eines geweihten kirchlichen Amtes zu geben, und es mag wohl sein, dass diesem Verlangen eines Tages Gehör gegeben wird. Ob das dann der erste Schritt auf einem Wege wäre, der schließlich zum Priestertum der Frau führte, ist die 


\section{Aoristo)))))}

International Journal of Phenomenology, Hermeneutics and Metaphysics

Frage. Dogmatisch scheint mir nichts im Wege zu stehen, was es der Kirche verbieten könnte, eine solche bislang unerhörte Neuerung durchzuführen. Ob es praktisch sich empfehlen würde, das lässt mancherlei Gründe für und wider zu. Dagegen spricht die gesamte Tradition von den Urzeiten bis heute, für mein Gefühl aber noch mehr als dies die geheimnisvolle Tatsache, die ich schon früher betonte: dass Christus als Menschensohn auf die Erde kam, dass darum das erste Geschöpf auf Erden, das in einem ausgezeichneten Sinn nach Gottes Bild geschaffen wurde, ein Mann war - das scheint mir darauf hinzuweisen, dass er zu seinen amtlichen Stellvertretern auf Erden nur Männer einsetzen wollte“ (ESGA 13,77). Auch wenn sie das Beachten der bis heute immer wieder angeführten Gegengründe in pragmatischer Hinsicht für angemessen hält, muss es für die damalige Zeit doch etwas Ungeheuerliches gewesen sein, wenn sie sagt: „Dogmatisch scheint mir nichts im Wege zu stehen," zumal sich bei einem Tischgespräch um den 30. März 1932 in der Kommunität Venio in München laut Chronikeintrag die Unterhaltung "einmal auch um die Frage drehte, inwieweit wohl später einmal eine Eingliederung der Frau in die Hierarchie, der wohl kirchenrechtliche, aber keine dogmatischen Hinderungsgründe entgegenstehen, denkbar wäre“ (Brief vom, 10.4.1973 an Sr. Amata Neyer). Das bedeutet, dass dieses Thema damals für Edith Stein durchaus relevant und nicht nur eine akademische Frage war, und wenn sie es dogmatisch für möglich hält, dann kann die Kirche ihrer Meinung nach das auch erlauben.

Ich denke, die Texte sprechen eine klare Sprache. Am Schluss sei mir eine Frage erlaubt: Können wir Männer dem Heiligen Geist Grenzen setzen? Das tun wir aber, wenn wir behaupten, er könne Frauen keine Berufung zum Priestertum schenken.

Eingereicht: 4. Juni 2021

Akzeptiert: 4. Juli 2021

Ulrich Dobhan

Toledo, v. 4, n'2(2021) p. 7-9 